Portland State University

PDXScholar

\title{
How Restorative Justice Practices Affect Adolescent Recidivism Rates: an Examination
}

Jordan A. Grant

Portland State University

Follow this and additional works at: https://pdxscholar.library.pdx.edu/honorstheses

Part of the Criminology and Criminal Justice Commons Let us know how access to this document benefits you.

\section{Recommended Citation}

Grant, Jordan A., "How Restorative Justice Practices Affect Adolescent Recidivism Rates: an Examination" (2020). University Honors Theses. Paper 857.

https://doi.org/10.15760/honors.878

This Thesis is brought to you for free and open access. It has been accepted for inclusion in University Honors Theses by an authorized administrator of PDXScholar. Please contact us if we can make this document more accessible: pdxscholar@pdx.edu. 
How restorative justice practices affect adolescent recidivism rates: an examination

$$
\text { by }
$$

\section{Jordan Grant}

An undergraduate honors thesis submitted in partial fulfillment of the requirements for the

degree of

Bachelor of Science

in

University Honors

and

Psychology

Thesis Advisor:

Marcus E. Sharpe, PsyD 


\begin{abstract}
This thesis explores the current implementation of restorative justice practices in various parts of the United States of America to determine if there is a link between the use of these practices and lowered recidivism rates. The literature reviewed for this paper span multiple juvenile justice systems giving a stronger view of how different states support victims, juvenile offenders, and the communities they impact at large. Through the literature found, the majority found the use of restorative justice programming reduced recidivism rates for the populations included in the samples. In future research, there is a continued gap in whether or not juvenile justice systems are implementing community specific cultural competencies into their restorative justice practices, as well as if restorative justice programs work in reducing recidivism rates of offenders with lengthier past criminal records.
\end{abstract}

Keywords: Restorative justice, cultural competencies, juvenile justice, recidivism 
How restorative justice practices affect adolescent recidivism rates: an examination

\section{Introduction}

The American justice system has changed a significant amount over time, going back and forth between policing strategies and ways the criminal justice system functions. In brief, the purpose of the criminal justice system at large is to hold people accountable for the crimes they commit, hoping to prevent future criminal acts from being committed. Unfortunately, the American justice system holds racial biases that contribute to citations, arrests, and imprisonment. This racial bias bleeds through policing strategies, court systems, the prison system, and policy implementation and enforcement. Based on what we know, these are difficult facts to deny, biases have shaped the functioning of the justice system America functions on. Though the criminal justice system has gradually changed over time, there are still flaws to be considered in both the juvenile and adult justice systems. The changes criminal justice have made throughout its existence have come in part to a response from changes within society.

In the early 1930s, policing became a practice focusing on patrolling and arrests. This method of policing divided the relationship between the police forces in America and the communities they served, creating distrust in police and unrest in their communities. That method of law enforcement began to shift in the 1970s, the American people demanded a change in policing practices. The policing strategy shifted to providing social services alongside enforcing the law (Blakely \& Bumphus, 1999). This is where the current criminal justice system stands; it claims to aim to prevent crimes from occuring, integrate policing in the community to build relationships within, and rehabilitate offenders before their return to society. Many different programs have been developed in an attempt to involve positive police presence in the 
community and make community members feel they had more of a hand in the system in order to recreate trust among them. This strategy is referred to as community policing, creating the bond between police departments and the communities they serve allows for stronger discourse, increased reporting of crimes, and trust in just enforcement of the law.

In the early 1990s, there were a couple violent juvenile crimes that caught the attention of the media, sensationalizing criminal acts of youth and inevitably sparking fear in American society. This led esteemed researchers in the criminology field to inaccurately predict the future of juvenile criminals to be "brutally remorseless" with no respect for human life (Equal Justice Initiative, 2014). These messages were unfairly directed towards Black and Brown youth, and gang-affected and involved youth, further creating a racial bias within the criminal justice system and society as a whole. This sparked the term "superpredators" to be coined in 1995 by political science professor John Dilulio who falsely predicted the dramatic influx of violent juveniles offenders over the following 15 years (Equal Justice Initiative, 2014). Policymakers and politicians responded to this manufactured panic and implemented laws in multiple states, giving some the ability to try youth as young as 13 as adults for committing serious crimes. These policies even allowed for youth to be tried for life sentences, which since has been overruled by the US Supreme Court to prevent automatic life sentences for juvenile offenders of violent crimes such as murder (Haberman, 2014). The policies put in place were seemingly highly unnecessary and appeared to be an overreaction to the inaccurate prediction taken in by the system and society as a whole.

Instead of violent crime rates steadily increasing, there was a sharp and steady decline in youth violence, falling by two-thirds the crime rate between 1994 to 2011 (Haberman, 2014). 
Dilulio has since admitted his faults, though the impact on the juvenile justice system and the youth it intends to serve cannot be reversed fully as the claimed research and policies put in place due to it has already negatively impacted many individuals and their families. Retracting the claim and acknowledging it as false also does not result in the masses changing their minds to coincide with updated research and facts; the impact of the "superpredator" claim still is evident in the discrimination and racial disparities within the juvenile justice system at large. The use of restorative justice philosophies and practices can help mitigate this fear, though only if there are cultural competencies considered in its implementation and execution.

Restorative justice programs aim to integrate law and the community; repairing relationships and in most cases creating commentary between the victim or community and the offender to have them understand the true impact of their actions. However restorative justice practices were not invented by researchers in the criminal justice system, these concepts have come from many indigenous cultures across the world. The concept of restorative justice has been in practice among many indigenous cultures prior to the development of the criminal justice theory it is based on. For example, in Native American and First Nation Canadian communities, they hold various community meetings that are similar in nature to the restorative practices created for the criminal justice system. These cultural practices showed an alternative way of working with offenders and the harmed individuals to begin the healing process and help the offender to work on changing the course of their path.

Restorative justice has been made into a criminal justice theory focused on repairing the relationship between the victim, community, and the offender to address the harm caused by the offense. This theory supports the idea that when we practice restorative justice, it will lower 
recidivism rates, meaning the offenders who are involved in these programs will be less likely to commit another crime. Restorative justice theory believes when the offender acknowledges and hears the pain and harm felt by the individual and/or community at large, they will understand the implications of their actions and learn from them. Often we see juvenile justice courts utilizing restorative justice programs with their youth as the theory aligns with the beliefs of rehabilitation and restoration in the juvenile court versus the adult criminal justice system which does not believe these programs to be a right to participate in (Rodriguez, 2007). Juvenile courts use practices that are intended to get the youth offender back on track to integrating into a non-criminal lifestyle instead of progressing into an adult offender. Restorative justice programs are implemented in the juvenile justice system to ultimately repair relationships with and protect the community at large, but it also helps to educate the offender and hold them accountable for their offenses (Rodriguez, 2007; Bazemore \& Griffiths, 1997; Bazemore \& Maloney, 1994; Umbreit \& Stacy, 1996; Umbreit \& Zehr, 1996).

There are four primary models of restorative justice used, victim-offender mediation (VOM), community reparative boards, family group conferencing (FGC), and circle sentencing. VOM and FGC work to bring the individuals who were affected by the crime, whether it is an individual, the community, or a combination of both to speak with the offender in order to promote accountability for the offenders actions working to repair the harm done to those who were affected. All four interventions have three main components in common; creating sanctions that are community-based, a less formal process, and decisions being made collectively versus from only an individual (Bergseth \& Bouffard, 2012; Bazemore \& Umbriet, 2001). These 
community-focused strategies were adapted to fit the criminal justice system as restorative justice practices, including the way restorative practices are implemented today.

Though there is a decent amount of research pertaining to restorative justice, there is not a lot of research to best understand what practices work best for specific demographics of offenders, or if cultural context is taken into consideration when implementing these programs. This thesis examines some of the studies conducted on the impact of restorative justice practices and whether or not they have reduced recidivism in juvenile offenders. Though it is not focusing on the other goals of restorative justice such as the reported impact on repairing the harm done in the community, which is an important aspect of restorative justice, this thesis looks to explore the influence these programs have on recidivism which would demonstrate the efficacy of restorative justice when working with the juvenile population. It is necessary to understand which restorative justice practices work for different demographics of offenders as not all programs will fit each juvenile justice community the same. The reasoning behind this is similar to why many assessments, programs, et cetera may not work when used in certain communities; cultural competencies should always be considered when creating and implementing systems. When we use the lense of understanding where the communities are coming from with a cultural context, a lot more progress can be made with the individual and the community at large. With this understanding, restorative justice programs cannot be as successful without considering the cultural lense of the individuals and community who will be impacted by it, both for the offender and victim. Part of what this thesis will explore is whether or not the restorative justice programs represented in the studies examined considered the cultural contexts of the communities they were implemented in, which may lead to more or less recidivism rates depending on the impact. 
Recidivism rates will decline in the juvenile population with effective restorative justice programming that is culturally competent to the population it is intended to serve.

\section{Literature Review}

As previously mentioned, the effectiveness of restorative justice programs has to do with how they are implemented in the communities they serve; it makes sense that there is not only one restorative justice program that works in lowering recidivism rates for all juvenile offenders. The article Examining the Effectiveness of a Restorative Justice Program for Various Types of Juvenile Offenders by Bergseth and Bouffard (2012) highlights the effectiveness in restorative justice practices across multiple demographics regarding recidivism. The aim of the study was to better understand whether or not the programs are effective in reducing recidivism rates for all kinds of juvenile offenders (Bergseth \& Bouffard, 2012). The demographics being considered are age group, gender (girls or boys, in this study), hometown (urban or rural), criminal history, offense type for studied charge (property or status offense, violent offense, or other), race or ethnicity, and risk levels.

In previous studies examined, this study points out the equity issue when restorative justice program personnel choose who is allowed to participate in the program. Often the individuals who have a higher risk level or are charged with a current violent offense are not selected to participate in a restorative justice program, skewing the data for who restorative justice programs work for (Bergseth \& Bouffard, 2012). The purpose of this study is to begin to bridge the gap in literature on age, gender, race or ethnicity, and prior offending behaviors determining the effectiveness of the program based on time between reoffense. 
This study focuses on a sample of 551 youth $(n=551)$ with $352(n=352)$ of those youth being referred to a restorative justice program in the Upper Midwest between 1999 to 2005. Out of the 352 youth referred to the restorative justice program, 67 were excluded from the study due to the referral conditions being tied to traditional court proceedings, while 18 youth had incomplete or missing data; the final sample number in the study who were referred to the restorative justice program was $284(n=284)$. The other $267(n=267)$ youth were referred to the traditional court proceedings and included in the study as the control group (Bergseth \& Bouffard, 2012).

The results of this study indicate restorative justice practices are effective for a larger range of offenders, contrary to the previous belief that low-risk offenders would be the only ones to benefit these interventions. In the analyses completed, they found eight statistically significant evidence their hypothesis was accurate. In 11 of 12 analyses conducted, individuals who engaged in the restorative justice program versus the traditional court proceedings had a longer time between recidivating no matter the demographics, previous, or current offenses the individual had (Bergseth \& Bouffard, 2012). These findings prove the hypothesis of restorative justice programs being effective for more than low-level offenders, opening up potential for all individuals regardless of demographic to be allowed to participate in restorative justice practices with the hope of lowering recidivism rates across all kinds of juvenile offenders using a rehabilitative approach.

The article Effectiveness of Various Restorative Justice Interventions on Recidivism Outcomes Among Juvenile Offenders by Bouffard, Cooper, and Bergseth (2016) explores their own call for further research on which restorative justice programming produced lower 
recidivism rates and aims to explore the restorative justice philosophy's impact on juvenile recidivism rates. As mentioned before, there are four primary different forms of restorative justice practices that are used in different programming. This research looks to understand the effectiveness of indirect or direct victim-offender mediation (VOM), community panels, or minimal interaction with restorative justice staff and programming to understand which approaches help reduce recidivism rates in juvenile offenders. Restorative justice practices give victims, the affected community, and offenders a chance to be a part of the justice system, giving all sides a chance to tell their stories and be heard. These programs have shown a large success rate in satisfaction with case outcomes, working to improve the offender's view of the procedural system and compliance with their orders, and ultimately reduce offender recidivism (Bouffard et al., 2016). Allowing individuals to participate in the criminal justice system is important in getting people to trust the system at large and to get the community to buy into the processes. Involving the offender in the creation of the process leading up to their sanctions can create trust for the systems in charge of their processing as these ordeals can be hidden from them, creating a divide between the individual and the justice system. The ways in which these restorative practices are administered can affect the recidivism rates of youth; the vast differences in methods of these practices by jurisdiction can impact recidivism rates. The current study seeks to find which programs produce long-term impacts on youth recidivism rates.

Victim-offender mediation (VOM) is a mediated discussion between the victim and offender used to hold the offender accountable for their crimes and to work on repairing the harm done to the victim. This is usually done as a face-to-face one time meeting mediated by a neutral party, though the study also chooses to have individuals participate in indirect VOM. Indirect 
VOM occurs when either the offender or the victim do not want to participate in direct conversation to repair harm.

Another type of restorative justice program this study used with referred offenders was a community panel. Community panels are used to create a less formal conversation between the community and the offender, usually ending in a contract between the community panel and the offender (Bouffard et al., 2016; Crawford \& Newburn, 2002; Karp, 2001). This style of restorative justice programming is generally used when there is not an immediate victim or if harm was done to the community at large or a business. When used in the juvenile justice system, the community panel takes on responsibility for submitting follow up reports about the offender's progress on fulfilling their reparations to the court.

This study uses the same data from the earlier study by Bouffard and Bergseth (2012), as mentioned in the article discussed earlier. This study used 551 youth involved in the juvenile justice system in the rural, upper Midwest of the United States from 2001-2005 ( $\mathrm{n}=551)$. The demographics of the studied youth that were considered for the data was race defined as white or non-white, age, gender defined as male or female, hometown defined as rural or urban, referral offense type defined as property, person, or other, prior contact with juvenile justice system, and the most serious charge they had of person, property, or other charge (Bouffard et al.,2016). 284 youth had been referred to the restorative justice programs, 267 youth were referred to attend traditional court proceedings. The restorative justice recommended youth were placed into either direct VOM $(n=155)$, indirect VOM $(n=44)$, or to participate in a community panel $(n=33)$. The remainder of the youth $(\mathrm{n}=52)$ had minimal or no contact with the restorative justice staff or programming, these cases either were introduced to the basic concepts of restorative justice and 
did not participate or were unable to be contacted (Bouffard et al., 2016). The results that came of this study determined that even at the level of minimal involvement in the restorative justice programming resulted in a reduction of recidivism, which shows that less intensive restorative justice practices can be effective depending on their risk rating for recidivism based on previous criminal history.

This study suggests using the less intensive practices, such as indirect VOM could be reserved for younger offenders who have been referred for their first crime, and reserve direct VOM and community panels for offenders who have a higher risk of recidivating as evidenced by recidivism in the past or increasing levels of harm with each crime committed (Bouffard et al., 2016). With respect to the suggestions of the outcomes of this study, it would make sense to begin with lower level restorative justice programming with low-level offenders in order to mitigate recidivism before the individual gails multiple offenses. Historical research on applying punishments for crimes proves that the punishment needs to match the intensity of the crime in order for the outcome to be successful, so applying a community panel to a first-time young offender may potentially do more harm and traumatic involvement for the individual.

Restorative Justice at Work: Examining the Impact of Restorative Justice Resolutions on Juvenile Recidivism written by Rodriguez (2007) looks to lessen the gaps in juvenile justice restorative justice research looking at the legal and extralegal reasons for recidivism rates in juveniles. Extralegal factors are defined as the individual's demographics and are unrelated to legal factors such as criminal offense history, probation involvement, et cetera. Unlike many studies in this area, Rodriguez (2007) uses data from a large metropolitan area with a racially and ethnically diverse juvenile offender population. The present study uses data from Maricopa 
County, Arizona in which Phoenix is located. Phoenix is the largest metropolitan area in the state of Arizona. In a previous study conducted by Rodriguez in 2005, data showed that individuals of color (Hispanic, Black, or Latino) were significantly less likely to be referred to participate in restorative justice programs than individuals who were White (Rodriguez, 2007; Rodriguez, 2005). The study conducted by Rodriguez in 2007 examines the effect of demographics such as gender, race or ethnicity, age, the referred offence type, or previous offenses affect their recidivism rates with being involved in the restorative justice program when compared to individuals who continued with traditional court proceedings, referred to as the comparison group (Rodriguez, 2007). While similar to the other studies examined in this literature review, this study seeks to understand if juvenile demographics play a role on the impact restorative justice practices have on their recidivism rates.

The current study uses data from the Maricopa County Juvenile Probation Department from 1999 to 2001 to determine the effectiveness of the implemented criminal justice committee restorative justice program. Maricopa County follows a philosophy consistent with the Balanced and Restorative Justice project (BARJ) created by the Office of Juvenile Justice and Delinquency Prevention of the U.S. Department of Justice. The programming used is similar to the restorative technique of community panels and family group conferencing, blending the two together being referred to as Community Justice Committees (CJCs). The committee consists of 2 to 4 trained adult individuals who volunteer to be on it, a juvenile probation officer, and the victim of the crime committed, if they wish to participate directly. The volunteers are trained on restorative justice practices before being able to participate on the board and receive ongoing training and assistance with restorative practices provided by BARJ (Rodriguez, 2007). Maricopa County’s 
implemented practice brings juvenile justice and the community together to deter juvenile recidivism with the intent of bypassing the traditional proceedings for a rehabilitative lense of working with the offender. Those excluded from participating in restorative justice programs are sex and violent property offenders, as directed by the jurisdiction in Maricopa County (Rodriguez, 2007).

The study findings showed that two years post release after attending a restorative justice based program only showed slightly lower recidivism rates compared to the control group who did not go through restorative justice practices. The findings show no significance between race and ethnicity, age, or offense type and lowered recidivism rates though showed significant effects of restorative justice on gender and past criminal involvement. The offenders who were placed in the restorative justice program with no prior offenses or one other prior offense demonstrated lower recidivism rates, as did female offenders (Rodriguez, 2007). Though the findings of this article are not consistent with this thesis' hypothesis, the content is important for understanding the role of collaboration in the juvenile justice system and how one implementation of restorative justice programming impacts different demographics exploring legal and extralegal conditions.

In Oregon, the juvenile justice system has implemented the Balanced and Restorative Justice philosophy in its restorative justice practices. The article Juvenile Justice in Oregon: Balanced and Restorative Justice in Action written by McMahan (2019) gives insight into how the Oregon juvenile justice system has implemented the restorative justice framework in four counties using the philosophies found in the Balanced and Restorative Justice (BARJ). BARJ was initially created by the Office of Juvenile Justice and Delinquency Prevention of the U.S. 
Department of Justice, and has been used in Oregon's juvenile justice system for the last 25

years. BARJ focuses on repairing the offender, the victim, and the community relationships that have been affected by the crime committed (McMahan, 2019). The values BARJ hold surround the idea of holding an offender accountable and releasing an ideally rehabilitated individual with an enhanced skill set for a successful reintegration back into the community.

The adoption of BARJ into the Oregon juvenile justice system was a response from a dramatic increase in crime, up 80\% in a wide range of offenses between 1988 to 1992 (McMahan, 2019). They seeked to implement policies to effectively manage juveniles in the system as the policies and programs in place at that time were intended for low level offenders or did not address the crimes being committed by youth at all. The juvenile justice system split from the Oregon child welfare agency and created the Oregon Youth Authority (OYA) on January 1, 1996 (McMahan, 2019). This allowed the balance between the juvenile's welfare and public safety to be attended to while holding the youth accountable for their actions. With the adoption of BARJ, juveniles involved in the system, the juvenile justice system, the victims of their crimes, and the community at large were able to come together to bridge the gap between criminal activity and a rehabilitative approach to restoring harm done in the community.

Each county in this review, Deschutes, Jackson, Douglas, and Clackamas counties discussed their implementations of the philosophies of BARJ into their restorative justice practices within their juvenile justice departments. In Jackson County, they utilize community panels as their restorative justice method and call it a Community Accountability Board (CABs). In using $\mathrm{CABs}$ and embracing BARJ, they recorded a six percent difference in juvenile 
recidivism rates when comparing restorative justice referred youth to those who completed traditional court proceedings between 2013-2017 (McMahan, 2019).

Similarly in Douglas County, a restorative justice program was implemented in 2006 named Roseburg Area Youth Services Program (R.A.Y.S.) using the BARJ philosophy. The R.A.Y.S. program utilizes a different restorative justice technique than those previously mentioned in the studies reviewed in this thesis, they use a Youth Court restorative technique to engage first time low-level juvenile offenders in community-based service projects to immerse them in community engagement. Youth Court is composed of juvenile volunteers who act as many roles adults would hold in a formal court setting such as defense and prosecuting attorneys, court clerk, bailiff, and jurors. These volunteers also sentence the offender and decide upon appropriate sanctions for them to follow through as a part of the sentence. The court itself is run by a judge who volunteers their time. This kind of practice is used around the country to repair harm done in the community by involving citizens in the process and further opt-in to being a member in their own community. R.A.Y.S. Youth Court uses a variety of sanctions to engage the offender including: restitution to the victim, community service acts, letters of apology, substance abuse assessment with the individual following through with recommendations, and serving on the youth court jury (McMahan, 2019). With the implementation of the R.A.Y.S. program, Douglas County observed a 4 percent drop in youth recidivism between 2013-2017, and juveniles who participated in R.A.Y.S. had a 33 percent lower recidivism rate than juveniles who were diverted to informal supervision between 2013-2017 (McMahan, 2019). The current practices implemented in Douglas County only allow low-risk, first time offenders to engage in 
restorative justice programs. This allows a specific demographic of offenders to engage, limiting the scope of the impact these programs have on a wide range of offenders.

The Clackamas County Juvenile Department (CCJD) began implementing BARJ philosophy and restorative justice practices when Oregon began to adopt them in the mid-1990s. As another added community tie to the restorative practice, Clackamas County trains volunteers, community partners, and community members on BARJ philosophies with quarterly training. Additionally, all employees of CCJD are required to attend these important training sessions. Being a community forward philosophy, their restorative justice program is named Community Connections, which is similar to the restorative technique of community panels. Through Community Connections, juveniles engage in community based reparations and healing the harm done by giving back (McMahan, 2019). The community projects assigned are designed to create meaningful tasks for juveniles that expand their own skill sets, increase self-confidence and awareness, and allow the community to connect with them in a positive way. CCJD also implemented a second restorative justice program focused more on victim-offender mediation (VOM) called the Victim Impact Program (VIP) (McMahan, 2019). As previously mentioned, VOM helps to repair harm between the victim of the crime and the offender, allowing the victim to process the impact the crime had on them and experience closure as the offender has the opportunity to show accountability for their actions. This section of the article did not provide data on the impact of restorative justice practices on recidivism from juvenile offenders.

McMahan offers an inside look into how restorative justice programming has shifted the juvenile justice system as a whole in Oregon by adopting BARJ philosophies within juvenile cases. Though there have been influences of restorative justice practices in this juvenile justice 
system, there is a long way to go when considering the demographics of offenders and who is referred to engage in these programs based on current research and studies.

At-risk youth are a vulnerable population who tend to be the individuals who unfortunately fall into the hands of the juvenile justice system. Youth who are identified to be 'at-risk' often have a higher number of risk factors than youth who are not involved in the justice system. Risk factors are variables such as low socioeconomic status, having abusive or neglectful caretakers, having incarcerated parents, low parental involvement or supervision, living in an unsafe neighborhood, exposure to substance use, etc. that impact the youth on an individual, familial, community, or peer level that increase the potential for them to be involved in criminal activity. The study Can At-Risk Youth Be Diverted From Crime? Authored by Wong et al. (2016) uses data from 21 studies found using inclusion and exclusion criteria determined by the research team to input into 20 databases over the course of 25 years (1990-2015) to determine which restorative justice programs have the most impact on juvenile recidivism rates and whether or not these programs are geared towards all of the youth they serve. Accurate research is crucial as it influences policy makers when deciding on which restorative justice practices would benefit their own communities, if any (Wong et al., 2016).

The current study included 21 studies with 5,209 participants $(n=5,209)$ identified to be in the treatment group category, or individuals who participated in restorative justice programs, and $13,049(n=13,049)$ participants identified to be in the comparison group category, or individuals who participated in traditional court proceedings. When conducting the meta-analyses of the studies included, they identified four characteristics to analyze: the delivery year of the program (1990-1999, 2000-2015), the research design, the sample of race or ethnicity 
of the study, and the sample size included. These characteristics have been identified throughout the existing literature as potential factors that impact the study outcomes, therefore were considered when analyzing the study data for relevance (Wong et. al., 2016). Of the 21 studies analyzed, 86 percent were found to be from non-peer reviewed sources, though when accounting for that discrepancy, the data found still was in favor of utilizing restorative justice practices. 12 studies showed statistically significant data the restorative practices implemented were effective at reducing juvenile recidivism rates; three studies showed the same results, though they were not considered statistically significant. Six studies found negative effects on juvenile recidivism, with five of those studies showing statistically significant data. Overall, the current study's findings showed positive and statistically significant results for the use of restorative justice programs and lowering juvenile recidivism rates (Wong et.al., 2016). The conclusion of this article highlights the need for more peer-reviewed studies and to conduct studies on restorative justice programs that are implementing policies and procedures from a culturally competent lense, which is an important gap that needs to be filled in the juvenile justice system.

\section{Discussion}

In the current literature, there have been mixed findings of whether or not restorative justice practices positively impacted juveniles in the system, in part due to there being no standardized program that works for all individuals who participate in restorative justice from a culturally competent lense. Most of the studies examined made little to no mention of cultural competencies when implementing restorative justice programs or the content of them, which is a large issue in the inequality of the justice system today. Alongside this issue is the reality of many contributing factors, both legal and extra legal, that play a part in the efficacy of restorative 
justice programs' impact on recidivism rates. Due to these factors, there has been no current research to determine which restorative justice programming, direct or indirect VOM, FGC, community reparative boards, or circle sentencing is the correct intervention for certain demographics.

The United States has the fortune of being culturally diverse with the unfortunate reality of instilled racism and racist practices within the systems that are designed to enforce laws and protect others. The racial injustices within the reformative systems reverberate into the juvenile justice systems; many assessments and programmatic functions were not created from a culturally competent lense, leaving people of color without the same access to resources and the same chances to succeed as their White counterparts. These disparities in the current research and systems make it difficult to assess whether or not the restorative justice programs are successful in reducing recidivism outcomes for all individuals, and whether they are using cultural competencies relevant to the demographics of the communities they serve.

The studies examined for this thesis also show there is likely a positive correlation to implementing restorative justice practices when working with juvenile offenders, though most of the studies examine a specific portion of criminal activity such as low-level offenders or first time offenders and generally do not include individuals who commit a crime against a person. Even though there is evidence these programs could be effective for more experienced offenders in increasing the time between offenses, or individuals who commit certain crimes against others (excluding crimes of sexual or of particularly dangerous nature) to participate in restorative justice programming, there is little evidence of implementing programs for higher risk offenders. 
If considering why the justice system considers itself rehabilitative in nature, examining what they do to intervene with juvenile offenders is crucial to gain understanding of the programming, support, and techniques they stand by for preparing an individual for re-entry into society, whether or not they were incarcerated. Not only do they consider themselves as rehabilitative, but as a means to ensure safety for the community when releasing an individual from incarceration or involvement with probation. In order to demonstrate an individual's preparedness for re-entry, the justice system is in charge of providing the youth with new skills, education to some level, reparations to the community from the youth, and hopefully a re-integrated individual that will not recidivate and end up back in the system, especially for a more damaging offense. If they only offer some of these programs to youth who have a longer offense history or their current offense being what is determined as a higher-level crime in their jurisdiction for their first crime, how is the true efficacy of restorative justice programming truly determined when the scope of offender demographics is narrow?

\section{Conclusion}

The initial hypothesis of this thesis was finding that restorative justice programmings would lower juvenile recidivism rates overall when engaging in a culturally competent model tailored towards the populations they serve. Upon analyzing the chosen studies, findings showed potential for this to be an accurate hypothesis with knowledge of a lack of research in how or if juvenile systems accomplish coming from a culturally competent lense when considering restorative justice. 
Though a small portion of the current research on restorative justice has been analyzed in this thesis, the general highlights of these studies was the continued significant gap in research on the impact of using restorative practices on non-White juveniles, offenders with serious crimes during the studies, or individuals who have more than one or two offenses. There is a definite need for understanding the impacts of restorative programming on these individuals as limiting access to a wide-range of offenders to a program that promotes further community and individual rehabilitation that could be helpful for offenders with more than one previous offense. In one study by Bergseth et al. (2016), their findings indicated evidence for the effectiveness of restorative justice programming used to work with juveniles who have longer offense histories to be positive in reducing recidivism rates, making a case for further research studies to be done on this demographic.

Specific research has not been identified to further investigate the implementation of cultural competencies in restorative justice programming. When dealing with any specific community, best practices show systems and providers should learn about the racial, cultural, and historical demographics such as past community-wide trauma exposure, socio-economic status, and population change. These factors among others build one's cultural competency; someone does not need to be directly from a community to be able to provide accurate, trauma-informed services that are tailored towards the individual's it strives to serve, however, they do need to gain a deep enough understanding of where individuals in that community come from to make a positive impact.

Further research should identify integration of cultural competencies in restorative justice programming for the communities they intend to serve with intention to create modifiable 
programs multiple juvenile justice systems with similar communities could implement and seek positive results in long-term reductions in recidivism. Researchers and policymakers should strive to widen the lense of restorative justice practices within the juvenile justice system in order to further the understanding of how these programs impact repeat offenders and if they find similar, widespread evidence of reducing recidivism rates among these youth. The implications of further research on these subjects could help policymakers implement effective and culturally competent restorative justice programs in their communities. This would assist in rehabilitating a wide range of juvenile offenders ensuring the needs of the victims and the communities are met while giving youth the opportunity to gain important skills and become positively engaged in their community and beyond. 


\section{References}

Blakely, C. R., \& Bumphus, V. W. (1999). American Criminal Justice Philosophy: What's Old-What's New? Criminal Justice Philosophy, 63(1), 62-66.

Bergseth, K. J., \& Bouffard, J. A. (2012). Examining the Effectiveness of a Restorative Justice Program for Various Types of Juvenile Offenders. International Journal of Offender Therapy and Comparative Criminology, 57(9), 1054-1075. doi:

$10.1177 / 0306624 \times 12453551$

Bouffard, J., Cooper, M., \& Bergseth, K. (2016). The Effectiveness of Various Restorative Justice Interventions on Recidivism Outcomes Among Juvenile Offenders. Youth Violence and Juvenile Justice, 15(4), 465-480. doi: 10.1177/1541204016647428

Bright, C. (n.d.). Victim Offender Mediation. Retrieved November 5, 2019, from $\underline{\text { http://restorativejustice.org/restorative-justice/about-restorative-justice/tutorial-intro-to-res }}$ torative-justice/lesson-3-programs/victim-offender-mediation/\#sthash.oyx0cySX.dpbs.

Haberman, C. (2014, April 6). When Youth Violence Spurred 'Superpredator' Fear. Retrieved May 19, 2020, from https://www.nytimes.com/2014/04/07/us/politics/killing-on-bus-recalls-superpredator-thre at-of-90s.html?smid=pl-share

Mcmahan, C. L. (2019). Juvenile Justice in Oregon: Balanced and Restorative Justice in Action. Juvenile and Family Court Journal, 70(1), 59-72. doi: 10.1111/jfcj.12126 
Mirsky, L. (2004). Restorative Justice Practices of Native American, First Nation and Other Indigenous People of North America: Part One. Restorative Practices E-Forum, 1-7. Retrieved from https://www.iirp.edu/pdf/natjust1.pdf

Rodriguez, N. (2007). Restorative Justice at Work: Examining the Impact of Restorative Justice Resolutions on Juvenile Recidivism. Crime \& Delinquency, 53(3), 355-379. doi: $10.1177 / 0011128705285983$

The Superpredator Myth, 20 Years Later. (2020, January 16). Retrieved May 19, 2020, from https://eji.org/news/superpredator-myth-20-years-later/

Watchel, T. (2016, November). Defining Restorative. Retrieved April 19, 2020, from https://www.iirp.edu/images/pdf/Defining-Restorative_Nov-2016.pdf 